\title{
The formation of land use at the waste storage facility of the pulp and paper industry
}

\author{
Vladimir Bogdanov ${ }^{1}$, Vitaly Garmanov ${ }^{1}$, Viktoriia Pavlova $^{1}$, Ekaterina Uvarova ${ }^{1}$, Aleksey \\ Osipov $^{2}$, Mikhail Arkhipov ${ }^{3}$, Aleksandr Nikonorov $^{4 *}$ and Luka Akimov ${ }^{4,5}$ \\ ${ }^{1}$ St. Petersburg State Agrarian University, Peterburgskoeshosse, 2, St. Petersburg-Pushkin, 196601, \\ Russian Federation \\ ${ }^{2}$ A.F. Mozhaysky's Military-Space Academy, Zhdanovskaya Naberezhnaya, 13, St. Petersburg, \\ 197198, Russian Federation \\ ${ }^{3}$ Federal State Budgetary Institution North-West Centre of Interdisciplinary Researches of Problems \\ of Food Maintenance, Podbelskogo shosse, 7, St. Petersburg, 196608, Russian Federation \\ ${ }^{4}$ Peter the Great St. Petersburg Polytechnic University, Polytechnicheskaya, 29, St. Petersburg, \\ 195251, Russian Federation \\ ${ }^{5}$ Politecnoco di Milano, 32 Piazza Leonardo da Vinci, Milano, 20133, Italian Republic
}

\begin{abstract}
The article provides materials on the natural restoration of land cover in the territory occupied by the waste storage facility of the pulp and paper industry. The article contains information on the level of soil fertility formed on this territory as a result of decomposition of organic waste over 25 years. The composition of the phytocenosis is presented. The article provides materials on the ecological state of the studied object, and also considers the technological operations of reclamation of an authorized landfill in the areas of forestry and recreational land use, taking into account the ecosystem formed at the storage facility.
\end{abstract}

\section{Introduction}

According to the Accounting Chamber, in the Russian Federation there are more than 1000 waste storage sites, about 15,000 official landfills and 17,000 unauthorized landfills, as well as about 13,000 unauthorized waste sites. Less than $40 \%$ of industrial and up to $10 \%$ of municipal solid waste is recycled in Russia. The total area under the waste storage facilities in Russia is about 4 million hectares. Solid household and industrial wastes are buried at landfills [1]. Garbage reform in Russia is designed until 2030.

In the post-Soviet period, the formation of landfills for waste storage was not given due attention. Old landfills with a large volume of waste storage were located spontaneously on the territory without taking into account a number of factors: the existing land categories, geomorphological, geological, hydrological conditions, terrain, etc. In addition, they did not have environmental engineering structures. These objects have become a serious source of environmental pollution. Therefore, resolving waste management issues in our country and preventing the reduction of land area under waste storage facilities is an important state task.

\footnotetext{
* Corresponding author: coolhabit@yandex.ru
} 
The reclamation of landfills allows the further use of reclaimed territories in the national economy.

In the Russian Federation, there are three types of storage of industrial and household waste: 1) landfills, which are engineering structures with the function of protecting them from possible environmental impacts; 2) authorized landfills that received permission in the postSoviet period for placement from the Department of Natural Resources and Environment, as well as sanitary and epidemiological stations for storage of waste in appropriate places; 3 ) unauthorized landfills.

The purpose of the research is to study the conditions for the possibility of using the landfill territory after its rehabilitation for various types of land use on its territory. The research objectives are as follows:

1. to study the morphological composition of the waste stored in the landfill;

2. to study the structure and agrochemical parameters of the surface (rootinhabited) layer formed as a result of decay of the organic material of the soil;

3. to study the impact of landfills on the ecosystem;

4. to conduct geobotanical studies;

5. to present rational technological operations for the restoration of an authorized landfill taking into account the state of the ecosystem on its territory for specific types of land use.

\section{Materials and methods}

The object of the study is the authorized landfill for industrial waste from a pulp and paper mill (PPM), the formation of which was allowed in the post-Soviet period by the Department of Natural Resources and Environment, as well as the sanitary and epidemiological station. The following methods are used in the study: cartographic, geobotanical, remote methods of chemical analysis, statistical, normative, comparative analysis. Studies are conducted on the territory of the facility for the storage of industrial waste from a pulp and paper mill (PPM). The total area of this facility is 17 hectares. The pulp and paper mill wastes were stored on the site of a sand pit for 25 years. During this period, an average thickness of about $25 \mathrm{~m}$ was formed from them at the industrial waste storage facility. For more than 5 years, waste storage has been discontinued here.

The largest amount for disposal at the quarry was pulp, paper, paperboard, bark waste mixed with calcareous earth, which amounts to $30-40 \%$ in terms of the amount of waste removed. Among the waste was wood and straw ash. According to the hazard class for the environment, these wastes belong to the IV-V hazard class.

In most of the territory of the pulp and paper mill (PPM) waste storage facility, soil cover has formed over 25 years due to the decomposition of stored organic waste (crust with wood chips, sludge, etc.) of various thicknesses from 15 to $40 \mathrm{~cm}$. Currently, the perennial grass grows at the largest parts of the waste storage facility.

\section{Results and discussion}

The results of the study of the morphological composition of the stored waste at the landfill showed that the composition of the upper root horizon of plants $(0-30 \mathrm{~cm})$ at the landfill (formed as a result of destruction of the organic part of the waste) is closely related to the vegetation growing here, since, vegetation is a bio-indicator of the state of soil cover and the environment. Therefore, the allocation of 2 main zones by vegetation on the territory of the landfill coincides with the qualitative condition of the soil in its upper layer. 
In the first zone, soil with the presence of poorly decomposed bark and wood chips (up to $25 \%$ ) of land and sludge is widespread to a depth up to $17 \mathrm{~cm}$. Undecayed rags, small stones, and polymeric materials are found in deeper layers. The storage of bark and earth here, as well as sludge, contributed to the formation of favorable soil for the life of meadow plants.

The soils of the second plant zone in the upper $(0-30 \mathrm{~cm}$.) horizon are mainly represented by construction debris, bark with earth, wood chips, sludge, and other components. The organic part, represented by sludge and crust with the earth closer to the central part of the landfill, decomposed up to $65 \%$. However, in the southern, as well as in the southeastern directions of the landfill, storage of lime sludge with an area of more than 1 ha is observed on its surface and at a depth of more than 1 meter.

In the influence zone of the landfill, a soil formed by a depth of more than $50 \mathrm{~cm}$. from the well-decomposed organic mass of the stored waste. It is characterized as fertile and suitable for both tree and plant growth. To assess the degree of fertility of the soil in the landfill, soil samples were taken to determine the content of the main nutrients for plants and other indicators affecting their livelihoods. Soil samples for agrochemical analysis were taken from various places of the landfill from the root layer up to $25 \mathrm{~cm}$. The results of agrochemical studies have shown that the modern soil fertility in this landfill is generally good. Here, soils with a neutral and alkaline reaction from low to high content of humus and organic carbon in the soil were formed, medium-rich and highly rich in phosphorus and potassium. (Table 1).

Table 1. Agrochemical composition of soil in the industrial waste dump of the pulp and paper mill in the root layer

\begin{tabular}{|c|c|c|c|c|c|c|c|c|}
\hline $\begin{array}{c}\text { No. of } \\
\text { pits for } \\
\text { samplin } \\
\mathrm{g}\end{array}$ & $\begin{array}{c}\mathrm{pH} \text { of } \\
\text { water }\end{array}$ & $\begin{array}{c}\mathrm{Ma} \mathrm{Mg}^{2+} \\
\mathrm{Mmol} / 100 \mathrm{~g}\end{array}$ & $\mathrm{Corg}, \%$ & $\begin{array}{c}\text { Humus, } \\
\%\end{array}$ & $\begin{array}{c}\mathrm{P}_{2} \mathrm{O}_{5}, \\
\mathrm{mg} / \mathrm{kg}\end{array}$ & $\begin{array}{c}\text { Probability } \\
\mathrm{P}_{2} \mathrm{O}_{5}\end{array}$ & $\begin{array}{c}\mathrm{K}_{2} \mathrm{O}, \\
\mathrm{mg} / \mathrm{kg}\end{array}$ & Probability $\mathrm{K}_{2} \mathrm{O}$ \\
\hline 1 & 7,7 & 20,8 & 0,95 & 1,63 & 14 & Medium & 358 & High \\
\hline 2 & 7,6 & 17,6 & 1,40 & 2,41 & 16 & Medium & 243 & High \\
\hline 3 & 7,7 & 15,2 & 3,50 & 6,02 & 16 & Medium & 190 & Low \\
\hline 4 & 7,6 & 30,4 & 7,50 & 12,90 & 24 & Increased & 368 & Increased \\
\hline 5 & 7,2 & 36,0 & 13,47 & 23,17 & 16 & Medium & 303 & Medium \\
\hline 6 & 8,4 & 20,8 & 4,31 & 7,41 & 36 & High & 610 & Very high \\
\hline
\end{tabular}

Note: 1 st pit - soil mixed with sludge (hor. $0-15 \mathrm{~cm}$ );

2nd pit - the soil is mixed with building material, decomposed sludge and organic waste (hor. $0-15 \mathrm{~cm}$ );

$3 \mathrm{rd}$ pit - the soil is represented by loamy mass (hor. $15-25 \mathrm{~cm}$ );

4 th pit - the soil presents well-decayed organic waste (hor. $0-25 \mathrm{~cm}$ );

5 th pit - the soil presents well-decayed organic waste (hor. $0-25 \mathrm{~cm}$ );

The 6th pit is a soil in the zone of calcareous sludge (hor. $0-25 \mathrm{~cm}$ ). (Vegetation is represented only by terrestrial mosses).

In order to determine the pollution of soil in the landfill with toxic and harmful substances, mixed soil samples were taken from horizons from 0 to $25 \mathrm{~cm}$. Zinc, lead, strontium, cadmium, phenols were determined in the soil taking into account the chemical composition of the waste stored at the landfill. According to the hygienic standards HS 2.1.7.2041-06 "Maximum allowable concentrations (MAC) of chemicals in the soil", the maximum permissible amount (MPA) of pollutants in the soil must comply with the 
following standards [2] (Table 2). Chemical analyzes of the soil of the landfill showed that the content of pollutants (zinc, lead, cadmium) in it is within the MPA. An exception is the increased amount of phenol in the soil, content of which was affected by the presence in the soil of incompletely decomposed bark and wood chips.

The results of the analysis of atmospheric air in the area of the waste storage facility indicate the absence of pollutants in the air, such as methane, hydroxybenzene (phenols), a mixture of saturated hydrocarbons that were below the MAC.

Table 2. Contaminants in the soil at the pulp and paper mill facility

\begin{tabular}{|c|c|c|c|}
\hline \# pt. & Indicator & $\begin{array}{c}\text { MPC (mg / kg) taking into account } \\
\text { the background (Clarke) }\end{array}$ & $\begin{array}{c}\text { Contents of polluting substances in } \\
\text { the soil in the soil (mg / kg) }\end{array}$ \\
\hline 1 & Zinc & 55,0 & 57,0 \\
\hline 2 & Lead & 32,0 & 17,0 \\
\hline 3 & Cadmium & 1,0 & 0,31 \\
\hline 4 & Benz(a)piren & 0,02 & 0.040 \\
\hline 5 & Phenols & 1,0 & 7,8 \\
\hline 6 & Strontium & Notinstalled & 0.78 \\
\hline
\end{tabular}

At 10-20 years of self-sowing, a phytocenosis from meadow plants formed at the industrial waste landfill of the pulp and paper mill on $2 / 3$ of its area. The species richness of plants in the phytocenosis is closely related to the climatic and soil conditions. The more favorable these conditions, the richer and more diverse the species composition of the plant community. The composition of the phytocenosis includes plants of various ecological groups according to the requirement of moisture, soil fertility and light. The diversity of environmental groups depends on microponosities and micropromotions. Among the meadow vegetation, dominant plants are distinguished, with a greater degree of occurrence in the phytocenosis and determining the degree of projective soil cover by plants and resistance to loss from the plant community: mother and stepmother (Tussilago farfara L.), pink clover (Trifolium hibridum L.), white melilot (Melilotus albus Medik), meadow fescue (Festuca pratensis Huds.). Based on the ecological groups of plants currently growing at the landfill, 2 main plant zones can be distinguished. The first zone is located in the eastern part of the landfill and captures its central part. The second one occupies a part of the center of the landfill and its western side.

In the first plant zone, the plant community is characterized by an abundance of species, which has 30 species of meadow plants. In this area, a grass-meadowis formed. It mainly grows mesophyte plants (medium in relation to moisture) and mesotrophic (average in relation to fertility level). Clovers dominate in the phytocenosis settle on slightly alkaline soils. White melilot occupies places with the presence of building debris in the soil. Thus, the vegetation at the landfill adapts to various living conditions. In general, noting the rather rich species composition of the phytocenosis in the first plant zone, we can note the suitability of the landfill grounds for sowing cultivated species of perennial grasses in order to use these lands as a recreational territory.

The second vegetation zone is located from the center of the landfill towards the southwest. It covers areas where construction debris, limestone sludge, bark with wood chips, etc. were previously taken out. An insignificant soil horizon of up to $17 \mathrm{~cm}$ was formed here, unsuitable for the settlement of forbs. A feature of this zone is a higher location on the landfill 
and alkalinity of the soil. This contributed to the settlement of plants drought-resistant and resistant to alkaline soils. Shrub growth occurs unitary. The ratio of plant species in the phytocenosis depends on the microrelief and the level of fertility of the root layer of the soil. Thus among the presence in the phytocenosis of cultivated species of perennial grasses that meet the requirements of biological recultivation on small slopes, mother and stepmother (Tussilago farfara L.) grow. The leading position among plants is occupied by white clover (Melilotus albus Medik) and yellow melilot, (Melilotus officinalis (L.) Pall.), which dominate in the phytocenosis with little involvement of weed forbs [3] (Fig. 1).

In places where there is calcareous sludge on the surface of the landfill, vegetation is absent. In microdepressions with a strong alkaline soil reaction, soil mosses and oppressed soddy pike (Deschampsia caespitosa (L.) Beauv.) grow curtains. Thus, the vegetation at the waste storage facility after the formation of the soil on it adapts to certain living conditions.

The above mentioned information allows us to draw the following conclusion: for biological reclamation of the landfill in this plant area additional soil application is necessary to create productive root habitable soil layer.

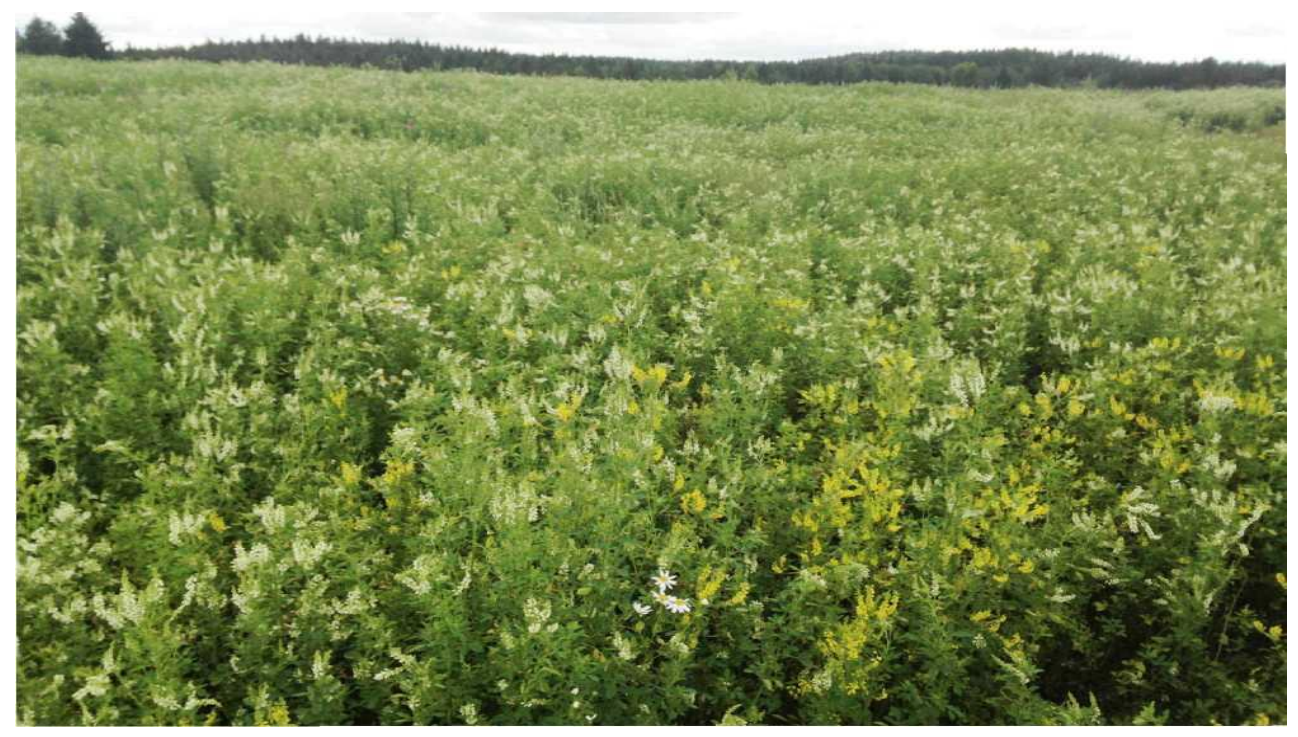

Fig. 1. Bean-herbaceous plant association with the dominance of white clover (Melilotus albus Medik) and yellow clover, (Melilotus officinalis (L.) Pall.) at the industrial waste landfill of PPM.

Taking into account the results of surveys at this waste storage facility, it should be noted in our opinion, that it is not advisable to carry out a full range of costly measures for its restoration for the introduction of these urbanized lands into economic circulation.

There are four main areas of reclamation of waste storage sites, such as agricultural, forestry, recreational and sanitary-hygienic. The direction of reclamation of landfills is agreed with the owners of the land. Reclamation of an object should take into account ecological, sanitary-hygienic and anti-erosion environmental requirements on the basis of existing ecological, sanitary-hygienic, construction, water management, forestry and other norms and standards, taking into account regional climatic conditions and the location of the site.

At the studied object (a waste mill of the pulp and paper mill) taking into account the ecosystem formed here for a long period (20-25 years), it is rational to use this territory after its surface improvement for forestry or recreational land use. 
The main stages of reclamation of the studied object should consist of 2 stages: technical and biological. Biological reclamation of the waste storage facility is mainly reduced to the formation of the soil layer, taking into account the need of plants for moisture and nutrients.

The technical stage should be performed both for forestry and recreational use of this facility. It consists of the following operations: garbage collection; filling pits; mowing grass; flattening slopes with the establishment of a slope skew of not more than 20 degrees; if necessary, surface planning with assembly in the herds of a fertile soil; scattering of soil from herds and fertile soil brought into the object. For forestry use of this territory, a digging of holes for planting trees to the required depth and a predetermined distance between them is provided, filling the pits with a layer of soil and planting forest species, followed by an earhouse. The biological stage of the reclamation of the pulp and paper mill facility includes a complex of agrotechnical measures, which consists of the following measures: dumping at least $20 \mathrm{~cm}$ of soil on the surface of the reclaimed land, suitable for biological reclamation, increasing the level of soil fertility in the root layer by introducing organic-mineral composts and mineral fertilizers in the norm calculated taking into account the agrochemical parameters of the soil, soil preparation for sowing and seeding of perennial grasses adapted to local growing conditions for phytocenoses of natural tinning, rolling in of sowing, planting trees and caring for forest plantations. When developing disturbed lands for forest plantations, it is advisable to limit ourselves to the ecological and social effect.

In the case of the recreational direction of the development of the reclaimed land, various options for evaluating the effectiveness are possible: the economic efficiency of using the territory for organized recreation and tourism along with obtaining an environmental and social effect, ecological and social efficiency when using the territory for other recreational facilities.

When creating educational and sports facilities on reclaimed disturbed lands, sufficient economic efficiency can be expected while ensuring an environmental and social effect [4].

\section{Conclusion}

When storing, pulp and paper waste, organic waste: bark, wood chips, paper waste, pulp, etc. mixed with earth, should be disposed of in the upper layer of the landfill to form soil as a result of decay of these components.

Organic waste (bark, wood chips, paper waste, cellulose, etc.) in the landfill body overgrow for 20-25 years with the formation of a soil fertile for plants. Five years after the formation of the authorized dump for the disposal of pulp and paper mill at the landfill, there were no significant environmental violations affecting the environment. Depending on the agrochemical composition and hydrophysical properties [5-9] of the formed soil at the waste storage facility, self-sowing cultivate perennial grasses, whose presence at the waste storage facility and the formed fertile layer should be taken into account during landfill reclamation.

Given the favorable conditions for plant life at the facility for the storage of pulp and paper plants, it is not advisable to use a full expensive set of measures for the reconstruction of the landfill. Environmental features of the "old" 25-year-old authorized landfill for pulp and paper industry allows us to recommend land reclamation for forestry and recreational land use. As additional research, the agroecosystems and the hydrophysical properties of the territories' soils and could be studied [10-17].

\section{References}

1. Web source: ach.gov.ru>press_center/publications-in-mass-... (date of reference: 10.02.2020) 
2. Gigienicheskie normativy GN 2.1.7.2041-06 «Predel'nodopustimye koncentracii (PDK) himicheskih veshchestv v pochve».

3. V.L. Bogdanov, A.V. Tudvachyov, Sb. materialov 6-Mezhdunarodnoj nauchnoj konferencii "Sovremennye problemy landshaftovedeniya i geoekologii", $95-98$ (rus)

4. V.V. Garmanov, V.L. Bogdanov, B.V. Zavarin, Nauki o Zemle 4, 7-10 (2015) (rus)

5. Terleev V.V., Mirschel W., Badenko V.L., Guseva, I.Y. (2017) An improved MualemVan Genuchten method and its verification using data on Beit Netofa clay, Eurasian Soil Science, Vol. 50, Issue 4, pp. 445-455 (DOI: 10.1134/S1064229317040135)

6. A. Nikonorov, V. Terleev, S. Pavlov, I. Togo, Y. Volkova, T. Makarova, V. Garmanov, D. Shishov, W. Mirschel, Procedia Engineering 165, 1741-1747 (2016)

7. V. Terleev, E. Petrovskaia, N. Sokolova, A. Dashkina, I. Guseva, V. Badenko, Y. Volkova, O. Skvortsova, O. Nikonova, S. Pavlov, A. Nikonorov, V. Garmanov, W. Mirschel, MATEC Web of Conferences 53, 01013 (2016)

8. V. Terleev, E. Petrovskaia, A. Nikonorov, V. Badenko, Y. Volkova, S. Pavlov, N. Semenova, K. Moiseev, A. Topaj, W. Mirschel, MATEC Web of Conferences 73, 03001 (2016)

9. O. Degtyareva, G. Degtyarev, I. Togo, V. Terleev, A. Nikonorov, Y. Volkova, Procedia Engineering 165, 1619-1628 (2016)

10. S. Medvedev, A. Topaj, V. Badenko, V. Terleev, IFIP Advances in Information and Communication Technology 448, 252-261 (2015)

11. V. Badenko, V. Terleev, A. Topaj, Applied Mechanics and Materials 635-637, 16881691 (2014)

12. A. Makarov, A. Mihailova, N. Arefiev, S. Pavlov, T. Chashchina, V. Terleev, V. Badenko, Procedia Engineering 117(1), 225-231 (2015)

13. N. Arefiev, V. Badenko, A. Nikonorov, V. Terleev, Y. Volkova, Procedia Engineering 117(1), 20-25 (2015)

14. A. Nikonorov, S. Pavlov, V. Terleev, N Arefiev, V. Badenko, Y. Volkova, Procedia Engineering 117(1), 258-263 (2015)

15. V.V. Terleev, W. Mirschel, U. Schindler, K.-O. Wenkel, International Agrophysics 24(4), 381-387 (2010)

16. R.A. Poluektov, V.V. Terleev, Russian Meteorology and Hydrology 12, 73-77 (2005)

17. V.V. Terleev, A.G. Topaj, W. Mirschel, Russian Meteorology and Hydrology 40(4), $278-285$ (2015) 